\title{
Should We Extend Voluntary Euthanasia to Non-medical Cases? Solidarity and the Social Context of Elderly Suffering
}

\author{
Andreas T. Schmidt \\ Assistant Professor, Faculty of Philosophy, University of Groningen, \\ The Netherlands \\ a.t.schmidt@rug.nl
}

\begin{abstract}
Several Dutch politicians have recently argued that medical voluntary euthanasia laws should be extended to include healthy elderly citizens who suffer from non-medical 'existential suffering' ('life fatigue' or 'completed life'). In response, some seek to show that cases of medical euthanasia are morally permissible in ways that completed life euthanasia cases are not. I provide a different, societal perspective. I argue against assessing the permissibility of individual euthanasia cases in separation of their societal context and history. An appropriate justification of euthanasia needs to be embedded in a wider solidaristic response to the causes of suffering. By classifying some suffering as 'medical' and some as 'non-medical', most societies currently respond to medical conditions in importantly different ways than they do to non-medical suffering. In medical cases, countries like the Netherlands have a health care, health research and public health system to systematically assign responsibilities to address causes of medical suffering. We lack such a system for non-medical suffering among elderly citizens, which makes completed life euthanasia importantly different from euthanasia in medical cases. Because of this moral 'responsibility gap', focusing on the permissibility of completed life euthanasia in separation of wider societal duties to attend to possible causes is societally inappropriate. To spell out this objection in more philosophical terms, I introduce the concept of acts that are morally permissible but contextually problematic.
\end{abstract}

\section{Keywords}

euthanasia - completed life euthanasia - physician-assisted suicide - autonomy solidarity - wellbeing - voltooid leven - contextually problematic acts 
The Netherlands was the first country to legalize voluntary euthanasia in medical cases. But several Dutch politicians, activists, and academics have recently argued that the law does not go far enough. If suffering and personal autonomy justify voluntary medical euthanasia (henceforth 'medical euthanasia'), then why not completed life euthanasia (henceforth 'CLE')? In completed life cases, healthy elderly people see no perspective for their own lives and hold a persistent wish to die, where their 'existential suffering' or 'life fatigue' is not primarily due to a medical condition.

Whether individual instances of CLE are morally permissible or not, not few of us feel uneasy about a society that responds to elderly suffering by facilitating their deaths. In this article, I try to spell out such a worry in more rigorous and philosophical terms. I first introduce the notion of acts that are morally permissible but contextually problematic. For example, an instance of euthanasia might have become permissible because people failed to discharge their antecedent duties. And this failure is what makes such acts contextually problematic. Imagine a society without universal healthcare. In such a society, instances of medical euthanasia might be individually permissible but contextually problematic. For had society discharged its collective medical duties, the moral reasons speaking for many instances of euthanasia would often not exist in the first place.

Different from most other articles on the topic, my article is not about whether, keeping all other things equal, individual CLE cases are permissible. In fact, I will remain neutral on this and claim that framing our societal approach to existential suffering this way is undesirable. Instead, my main contention is that CLE is contextually problematic. Compare our current treatment of CLE with cases of medical euthanasia. Countries like the Netherlands have high-quality universal healthcare and public health that assigns responsibilities to try to prevent the causes that lead people to request euthanasia for medical reasons. Yet when suffering is labeled 'non-medical', we typically lack a system that assigns responsibilities for the prevention of existential suffering. This responsibility gap makes focusing on CLE in isolation of other relevant collective duties a societally inappropriate response (arguably, in a way that medical euthanasia is not - although I soften the contrast later in the article).

Readers outside the Netherlands might find it outlandish to even discuss versions of euthanasia as permissive as CLE. But the discussion matters beyond the idiosyncratic Dutch context (Huxtable and Möller 2007). First, while many readers might feel uneasy about legalizing CLE, spelling out why is a philosophical challenge. Second, various countries and states in the US have recently taken a more liberal stance towards medical euthanasia. Accordingly, 
questions regarding the moral limits of voluntary euthanasia arise there too. And my Contextual Justification Argument applies not just to CLE but other forms of euthanasia too. For example, can we justify euthanasia in psychiatric cases? And, if so, what kind of collective duties in the prevention and treatment of mental illness do we need to discharge first? Finally, this article makes theoretical contributions. The concept of 'contextually problematic action' is theoretically fruitful beyond euthanasia debates. Moreover, the article raises fundamental questions in moral and political philosophy. How far does the state have duties to respect people's autonomy, promote wellbeing and protect human life, and how far are these duties at all compatible?

I proceed as follows. In section 2, I outline the Dutch debate around CLE. I briefly discuss the central argument for CLE in section 3. In section 4, I introduce the idea of contextually problematic acts. In sections 5, 6, and 7 I develop the Contextual Justification Argument. In section 8, I return to the comparison between medical euthanasia and CLE. In section 9, I discuss two objections. I conclude in section 10.

\section{Completed Life Cases in the Netherlands}

Killing, assisting someone's suicide, and performing voluntary euthanasia are illegal in the Netherlands. However, if performed by a physician, voluntary euthanasia and physician-assisted suicide (I refer to both simply as 'euthanasia') are allowed, if medical suffering is irreversible and perceived to be unbearable, due care has been exercised by the physician, and the patient expresses a voluntary, competent, and stable wish to die.

In 1998, a famous court case tested the limits of Dutch euthanasia laws. Healthy 86-year-old Edward Brongersma - a controversial personality in his own right - sought physician-assisted suicide because of existential suffering. His physician helped him commit suicide and was later found guilty but not punished. The Dutch Supreme Court upheld this ruling. A widespread national discussion of CLE ensued. In 2014, the Liberal-Labor coalition government called in a committee to assess legal options for CLE and announced plans to table a bill legalizing CLE in the future. The committee also commissioned a comprehensive report on CLE, frequently referred to as the 'Schnabel report' (Schnabel et al. 2016). ${ }^{1}$

1 The current multi-party coalition government has made such legislation more difficult, but the debate continues nonetheless; see "Dutch Coalition Negotiations: 'Compromise Reached on Ethical Issues"' 2017. 
What is a 'completed life' (voltooid leven in Dutch)? This somewhat infelicitous term can refer to miscellaneous life situations. The Schnabel report offers the following definition: 'These are persons, typically of old age, who in their own opinion lack a life perspective and who, as a result, have developed a persistent and active wish to die' (Schnabel et al. 2016, 34) [translated from Dutch]. Note two important qualifications. First, CLE is different from euthanasia in psychiatric cases, which in principle is legal in the Netherlands. Second, some putative CLE cases actually qualify for medical euthanasia. Dutch law allows for euthanasia when smaller medical ailments 'add up' to a medical condition which a person finds unbearable. This applies to many putative CLE cases but not all. While precise estimates are not available, the number of genuine completed life cases in the Netherlands might be small (Schnabel et al. 2016, 109-11). Of course, more systematic surveys might uncover more cases and the number should be greater in more populous countries.

In section 3, I now give a brief overview of central arguments for CLE.

\section{The Argument from Arbitrary Difference}

Autonomy and wellbeing are the two central considerations in favor of medical euthanasia, both in philosophical discourse and legislation (Brock 1992; Sumner 2011; Young 2007, 2016). The central argument for CLE is what I call the Argument from Arbitrary Difference: if a concern for people's autonomy and wellbeing justifies medical euthanasia, it also justifies CLE. Drawing a distinction between the two is morally arbitrary (Dijkstra 2016; Huxtable and Möller 2007; Varelius 2014).

Take autonomy first. Autonomy is typically taken to require that one be in an adequate position to pursue one's conception of the good (I say more about autonomy below). Arguably, autonomous agents should also be able to determine the circumstances of their own death. We should thus take people's expressed wishes on how to die very seriously. Moreover, in medical cases, persons in the final stretches of their life often strongly depend on other people and experience lowered physical capabilities and control over their own bodies. Such reduced capabilities mixed with heightened dependency often hamper autonomous living. ${ }^{2}$ Proponents of CLE agree. But they hold that

2 In line with the Dutch debate - and the wider ethical discussion - I focus on wellbeing and autonomy as the central justificatory reasons and exclude dignity here. It clearly matters whether people perceive their situation as dignified or not. However, this perception can differ strongly between persons. For example, some patients perceive dependency on 
particularly the first consideration, respecting people's expressed wishes, applies to completed life cases too. Why should we respect the wishes of patients but not healthy citizens?

Note, however, that the defence of CLE does not rest exclusively on consent. I here exclude the so-called 'pure autonomy view': under a strong interpretation of the volenti non fit injuria principle, killing another person is not wrong at all, if consent has been given. On this view, consent is necessary and sufficient to justify euthanasia. This principle trivially justifies voluntary CLE. ${ }^{3}$ I exclude this position here. Such a view would allow all forms of voluntary killing and assisted suicide - even for healthy and happy young people. Moreover, such a view is incompatible with a widely recognized state duty to protect human life and with many other laws, such as those prohibiting voluntary slavery. Importantly, this view clashes with existing frameworks for medical euthanasia. In bioethical and legal discussions, autonomy and wellbeing are thought to 'work together' and be jointly necessary in the justification of euthanasia, which is also the case in Dutch euthanasia law (De Haan 2002; Sumner 2011; Young 2007). Finally, even proponents of CLE make their case invoking both autonomy and wellbeing.

The second argument for euthanasia is wellbeing. Patients seeking medical euthanasia experience their lives as being marked by either suffering or an intolerable absence of wellbeing. 'Wellbeing' is here understood very broadly covering nearly all aspects relevant to someone's quality of life. Importantly, 'wellbeing' here is not meant to be exclusively or even primarily about physical pain. Only a minority of patients (around 30\%) mention pain as their primary reason for requesting euthanasia. Patients more often mention loss of autonomy, not being able to engage in activities that make life enjoyable or valuable, losing control of bodily functions, loss of dignity, and being a burden for others as some of their reasons for requesting medical euthanasia ("Oregon Death with Dignity Act: Annual Report" 2019, 12; Emanuel et al. 2016, 85). As I take 'autonomy' and 'wellbeing' to be very broad, most items on that list can be covered by these terms. With this broad understanding, a common argument

caregivers as undignified, while many others do not. Therefore, how far 'dignity' provides a reason - either in favor or against euthanasia - highly depends on the patients' own perceptions and desires. Given that I construe autonomy and wellbeing broadly, this should cover relevant dignity concerns (or so I assume).

3 One might worry that this view cannot justify forcing anyone to administer CLE. But this problem could be circumvented institutionally by recruiting end-of-life consultants who voluntarily provide CLE. 
is that euthanasia can help patients prevent unnecessary suffering or having to go on living a life with a quality of life the patient finds unbearable.

Proponents of CLE now argue that existential suffering is no less real just because its cause is non-medical. Various reasons suggest taking existential suffering seriously. First, bioethicists know that it can be difficult to draw a sharp distinction between what is medical and what is not (Huxtable and Möller 2007, 123-24). Given significant vagueness, our idea of what is medical might not justify dismissing existential suffering. Second, even in medical cases, assessing someone's suffering includes strongly subjectivist elements. A patient's subjective experience of her condition is a central consideration in medical euthanasia decisions. If someone judges their life as worthwhile despite medical challenges, medical practitioners respect the patient's judgment. Conversely, if we take the subjectivist component seriously, should it not apply in non-medical cases too? It seems that barring obvious subjective misperceptions about her own current and future wellbeing, a person who does not want to continue living should be taken seriously.

The Argument from Arbitrary Difference contends that justifying medical euthanasia in terms of autonomy and wellbeing implies CLE. I here do not discuss existing arguments against CLE nor all responses to the Argument from Arbitrary Difference. A short list should include the following. First, decisions on whether to allow CLE should not fall within the medical professional's purview. ${ }^{4}$ Second, CLE might jeopardize the acceptance of medical euthanasia and gives fodder to those worrying about a slippery slope (Huxtable and Möller 2007, 124). Fourth, CLE might be abused, for example, when elderly might be pressured into euthanasia. Fifth, the distinction between nonmedical and medical suffering is morally relevant. Moreover, despite vagueness, we can often enough distinguish clear-cut cases. For example, most euthanasia requests come from patients with cancer and some others from patients with neurodegenerative conditions. Even without a theoretically perfect definition, we can identify these as being medical. Finally, when someone wishes to die without an 'objective' medical reason, then this might itself indicate that she is insufficiently rational to consent to euthanasia. ${ }^{5}$

Note that in this article I do not assess whether such arguments and objections work or not, nor do I assume that we can easily uphold a strict analytical distinction between what counts as medical and what does not (I remain

4 See Varelius (2014) for a response. Dijkstra (2016) suggests that CLE could be administered by end-of-life consultants rather than doctors.

5 Kissane (2004), for example, argues that 'demoralization' should often be treated as a psychiatric disorder. 
neutral on this point). Instead, my aim is to provide a new and different angle on the issue, one that can account for the vague but pervasive feeling that there might be something societally inappropriate about CLE. I also leave the comparative issue - whether CLE is relevantly different from medical euthanasia aside for now. My argument in the next section is specifically about CLE. Only in section 8 do I come back to some comparative issues between medical and non-medical euthanasia.

\section{Contextually Problematic Actions}

To make my argument, I first introduce some philosophical apparatus. Consider the following cases:

Crevice 1: person A can easily prevent B from falling down a crevice. To avoid a minor inconvenience, A does not prevent B's falling in. Being stuck and suffering immensely with no prospect of escaping or being rescued, B then asks A to come down and kill them, and A complies.

Crevice 2: B was unluckily swept off their feet by a surprisingly strong gust of wind. As a result, B falls into the crevice. Person C walks by the crevice. Being stuck and suffering immensely with no prospect of escaping or being rescued, $\mathrm{B}$ asks $\mathrm{C}$ to kill them, and $\mathrm{C}$ complies.

Let us assume that killing B is permissible in both cases. But we intuitively think the cases also differ. Imagine someone compared A's and C's acts of killing and completely abstracted away from how they came about. She might treat both acts as equivalent, seeing that the moral reasons for and against killing are the same. Such an analysis would seem problematically incomplete. Consider next:

Crevice 3: Every year, several people fall down the crevice in society S's territory. Policymakers in S discuss what to do about it. They consider whether to legalize and facilitate voluntary euthanasia for those who fall into the crevice. They correctly conclude that euthanasia is morally permissible in each instance. Alternatively, they could build a fence that would perfectly prevent people from falling into the crevice. They do not actively consider the fence and decide to legalize euthanasia to be administered by trained specialists. After all - they reason - each instance of euthanasia is morally permissible. 
Something is clearly off about how the policymakers reason about euthanasia: even if each instance of euthanasia is morally permissible, the overall practice seems an inadequate collective response. We can also weaken the case a little bit. Rather than knowing full well what option would prevent people from falling into the crevice, our policymakers might confront some uncertainty.

Crevice $3^{*}$ : Everything is as in Crevice 3, except this time it is not obvious how best to prevent people from falling into the crevice. Some measures, such as a fence, are potentially effective but that would require further investigation. To save time and effort, policymakers instead legalize euthanasia. After all, all instances of euthanasia are permissible.

Even though it is not obvious what the preventive options are, or whether there are good preventive options, the policymakers' simple reasoning - euthanasia seems morally permissible in each instance - still seems to betray a societally inappropriate response.

I describe the instances of euthanasia in cases such as Crevice 1,3 , and $3^{*}$ as contextually problematic. An act can be contextually problematic even if it is permissible and/or right. A practice is contextually problematic if enough of its constituting acts are contextually problematic. Contextually problematic acts and practices carry the following properties.

First, an act becomes contextually problematic through its causal moral history. An act's causal moral history is about what caused the moral reasons for and against the act being present. For example, in Crevice 1, B is suffering immensely, has no hope of escaping the crevice, and has expressed a desire to be killed. The causal moral history is about what caused such pro tanto moral reasons to be present. When an act is contextually problematic, the moral reasons for and against doing it are, at least partly, attributable to someone failing to discharge their antecedent duties (or of acting wrongly in some sense). For example, the factors that make it permissible for A to kill B in Crevice 1 came about because A had failed to prevent B's falling into the crevice.

Second, we have moral reasons to prevent situations in which acts become morally permissible but contextually problematic. The weighty pro tanto reasons against doing the contextually problematic act typically give us reason to prevent these factors from becoming moral reasons. ${ }^{6}$ For example, in Crevice 1,

6 Such duties vary with the degree to which acts are contextually problematic. Imagine that A accidentally drops a banana peel and B is walking behind A. It's permissible of me to block B's way to prevent her from slipping on the banana peel. This is contextually problematic but only mildly so: the moral reason against my interference is relatively weak and 
3 , and $3^{*}$ someone gets killed. If we think that we ought to prevent killing and premature death, as I think we should, then we typically have moral reason to prevent situations in which an act becomes permissible or even right despite it involving killing someone.

In Crevice 3 and $3^{*}$, policymakers only focused on whether acts of euthanasia are permissible or not. They ignored that such acts are contextually problematic. Ignoring that an act is contextually problematic implies that one morally assesses such act in separation from its causal moral history, which I call deontic isolation. Deontic isolation can be both instrumentally counterproductive and relationally inadequate. Let us start with instrumental reasons.

In Crevice 3 and $3^{*}$, policymakers and legislators engaged in deontic isolation and ended up recommending a practice of legalized euthanasia. But deontic isolation and, concomitantly, policy isolation can have undesirable effects.

First, such deontic isolation might make us less likely to do more to discharge antecedent duties. Focusing on the legalization and permissibility questions might push other options off the agenda, making it less likely to investigate and consider alternative policy approaches. Relatedly, our frame might affect what we prioritize. For example, we might direct our attention towards removing obstacles currently standing in the way of a permissible practice of euthanasia. Accordingly, we might focus on making euthanasia more efficient, installing safeguards to prevent abuse, making euthanasia more dignified and so on. Such factors might then be prioritized over other factors, particularly preventive efforts. Moreover, such prioritization can be path-dependent and thereby have prioritizing effects long down the line (Pierson 2000). ${ }^{7}$

Second, compared with the status quo, deontic isolation might even make us less committed to attending to antecedent moral duties than we currently are. For example, the society in Crevice 3 and $3^{*}$ might end up doing even less to prevent situations in which people request euthanasia. Their feeling might be that the problem has become less serious, so our efforts to prevent the problem can be scaled down somewhat.

Of course, the above instrumental effects are empirical and for issues like euthanasia they remain somewhat speculative. But that they pose a non-negligible

the peel-dropping pedestrian's moral failure not dramatic. Cases like Crevice 1,3 , and $3^{*}$ are different. After all, they involve matters of life and death. As this article is primarily about euthanasia, I exclude 'weak' contextually problematic cases.

7 Of course, the reverse effect is possible: compared with a situation in which we simply ignore the whole issue, raising the legalization question might make it more likely that we also talk about our antecedent duties. While this might be true, my point is merely that once the issue is on the table, deontic isolation can make it less likely that we focus on antecedent duties. 
threat should be taken seriously such that we should give them some credence but, of course, not full credence. But besides instrumental reasons, deontic isolation can also be non-instrumentally or relationally inappropriate.

First, deontic isolation can betray a lack of solidarity. I understand solidarity as 'shared practices reflecting a collective commitment to carry 'costs' (financial, social, emotional, or otherwise) to assist others' (Prainsack and Buyx 2012). Solidarity implies a collective commitment to values, typically involving a sense of sameness or commonality between people who are solidaristic with each other. Moreover, many forms of solidarity - not all - are partly instantiated in formal institutions. In this, solidarity differs from altruism for example. You can be altruistic towards someone with whom you share very little if anything (say when a Finnish animal rights activist is altruistic towards cattle in Iowa). Moreover, such altruism can be spontaneous and individual rather than practice-based and collective. In Crevice 3 and $3^{*}$, policymakers analyze instances of medical euthanasia independently of their causal moral history. Analyzing each instance separately from its social context, their response reflects a lack of solidarity, as it reflects a failure to view individual suffering as a challenge to be addressed collectively rather than just individually.

Second, and relatedly, how we approach a problem through policy and legislation has an expressive dimension. In a classic paper, Lawrence Lessig shows how laws and public policy do not only regulate behavior but can also construct social meaning (Lessig 1995). Similarly, through deontic isolation, lawmakers can influence how we interpret individual suffering and unhappiness and our normative expectations towards it. In Crevice 3 and $3^{*}$, for example, we might worry that if the societal approach towards those falling into the crevice consistently relied on deontic isolation, the phenomenon of people falling into the crevice would appear as a natural phenomenon society should deal with after the fact. Or consider a different, more familiar example. In discussions around obesity, blame is often placed on those who are obese, oftentimes connecting obesity to lack of self-control. Here, we might imagine that deontic isolation for example, whether healthcare systems are justified to charge obese patients more - might contribute towards reconfiguring the meaning of obesity. Through deontic isolation we might interpret obesity primarily as an individual failing and disassociate it from its collective, public health dimension.

Third, those who justify euthanasia typically invoke autonomy and wellbeing. But to invoke such values coherently, one ought to acknowledge how autonomy and wellbeing matter in the causal moral history of instances of euthanasia requests. With deontic isolation, we might well fail in one of two ways. Either we are being disingenuous: we might pretend to be committed to invoke autonomy and wellbeing but hide how we shirk on our responsibilities 
elsewhere. Less dramatically, we are not disingenuous but only incoherent in our values. Unintentionally, we fail to see that invoking autonomy and wellbeing commits us to a broader range of societal obligations outside of individual euthanasia cases. ${ }^{8}$

So, I think there are good reasons against deontic isolation when actions are contextually problematic. Note that this does not mean that being contextually problematic is part of the 'fundamental structure' of morality. We could, for example, analyze cases like Crevice 1 without the concept of 'conceptual problematic acts': Was it right or wrong of A not to prevent B from falling? (Answer: wrong) Was it right of A to help B die? (Yes, we assume.) But this is compatible with my claim: in real-life contexts, how we frame a moral question and what questions we prioritize in political and legal debates can itself become a moral question. And we can have strong instrumental and non-instrumental reasons against deontic isolation.

I now argue that, whatever else might be objectionable about it, in our current approach to CLE we fail to consider what would make instances of CLE contextually problematic.

\section{$5 \quad$ The Contextual Justification Argument}

When we seek to justify a practice of euthanasia, I suggest we ought not to consider instances of the practice in isolation from their causal moral history. Instead, we should aim for what I call 'contextual justification' which imposes stronger requirements than 'case-based justification.'

Case-Based Justification: A practice of legalized voluntary euthanasia is justified in a case-based sense, if and only if (enough) instances of it are morally permissible (and maybe often enough right).

A practice can be justified in the case-based sense, even if all its instances are contextually problematic. Contextual justification implies case-based justification plus something else:

Contextual Justification: A practice of legalized voluntary euthanasia is contextually justified if and only if (i) (enough) instances of it are morally permissible (and maybe for the most part right) and (ii) justifiable

8 Of course, all three points are somewhat related. We can only legitimately claim to embody solidarity if our commitment to assisting each other is minimally coherent. 
and sufficient efforts have been undertaken to prevent this practice being contextually problematic.

Now what are these 'justifiable and sufficient efforts'? The idea is that we can undertake efforts that would remove, or lessen, the moral reasons that speak for euthanasia in individual instances. Persistent suffering and a persistent wish to die speak for allowing euthanasia - without necessarily being decisive if we take autonomy and suffering seriously. To prevent instances of euthanasia becoming contextually problematic, we ought to prevent individuals suffering so strongly that they persistently wish to die. The first premise of my Contextual Justification Argument is this:

Premise 1: A practice of legalized voluntary euthanasia is contextually justified if and only if (i) (enough) instances of it are morally permissible (and maybe often enough right) and (ii) justifiable and sufficient efforts are undertaken, both societal and individual, to prevent situations in which individuals, to whom the practice could apply, wish to be killed.

Let me elaborate a little.

First, what makes efforts 'justifiable'? Premise 1 does not cover all humanly possible preventive efforts. In researching and pursuing possible efforts, other moral goals and constraints will apply. For example, our efforts should not grossly violate other moral constraints or be unjust, for example. Moreover, such efforts should compare favorably with alternative uses of time and resources. We need not, for example, move our entire government budget towards preventing every medical euthanasia case. Finally, we should have reason to believe that such efforts have a decent chance of being successful.

Next, when are such efforts 'sufficient'? There is no obvious way to precisely locate the sufficiency threshold. But such vagueness does not undermine my primarily institutional argument. Minimally, to undertake sufficient efforts requires a system that (i) researches what actions are available and have reasonable chances of success (remember Crevice $3^{*}$ ), (ii) formulates relevant duties, (iii) assigns responsibilities for such duties, and (iv) reliably discharges such duties. Such institutions need to do (i) to (iv) sufficiently well. While this framework does not dispel all vagueness, it tells us which institutional efforts a society needs to undertake to sufficiently meet its preventive duties. Finally, note that such institutions can include informal institutions. While formal institutions will bear the brunt of these efforts - particularly state institutions informal institutions, pertaining to civil society and people's private lives, will 
be important too. ${ }^{9}$ Solidarity requires a collective commitment and such a commitment typically extends beyond formal state institutions. Of course, in my formulation, whether we meet antecedent duties is presented as binary. I do so for simplicity. More plausibly, if such duties are various and themselves sometimes a matter of degree, contextual justification would then become more a matter of degree.

The argument I want to advance is the following.

Premise 1: A practice of legalized voluntary euthanasia is contextually justified if and only if (i) (enough) instances of it are morally permissible (and maybe often enough right) and (ii) justifiable and sufficient efforts are undertaken, both societal and individual, to prevent situations in which individuals, to whom the practice could apply, wish to be killed.

Premise 2: In countries such as the Netherlands and with respect to a practice of CLE, it is not the case that justifiable and sufficient efforts are undertaken to prevent situations in which relevant individuals - those who see their lives as completed - wish to be killed.

Conclusion: In countries such as the Netherlands, a practice of CLE is not contextually justified.

9 This invites a Rawlsian critique: justice is about the basic structure of society. Contextual justification should thus not entail obligations largely actualized in individual decisions. I exclude this point here. First, I am convinced by Cohen's critique (Cohen 1997). Second, justice is not the only normative value involved in my argument. As we will see below, debates around euthanasia typically fall outside the Rawlsian framework. Finally, I find a sharp distinction between the basic structure and individual behavior hard to sustain. Or, if you understand 'basic structure' more broadly, then it will go far beyond formal state institutions. Consider, for example, public health initiatives that persuade people to quit smoking and that seek to change social norms. Such interventions involve state action but are largely located in individual decisions and informal institutions. Similarly, the social integration of the elderly and the reduction of loneliness - which I discuss below - will involve a mix of state action, civil society, norm changes, and individual behavioural change. Some people distinguish between 'government' and 'governance.' Government is restricted to formal state action in a limited sense, whereas governance implies that successful state interactions work in tandem with non-governmental institutions and individual citizens. Public health interventions typically require good governance as do the preventive duties I talk about in this article. 
For now, grant me premise 2 (which I defend below). Consider now how the aforementioned reasons why we should care about 'contextual justification' can apply to CLE.

I listed the instrumental worry that deontic isolation might make us less likely to do more to discharge antecedent duties or, worse, it might make us do less than we currently do and have path-dependent prioritizing effects long down the line. Applied here, focusing narrowly on whether we should allow CLE whilst keeping everything else equal might lower the likelihood with which the antecedent reasons for existential suffering are addressed. Again, note that given the empirical nature of this claim we should give it some but not full credence.

I also argued that deontic isolation can be non-instrumentally problematic.

First, by focusing narrowly on the permissibility of individual instances of CLE without attending to the wider social context and antecedent duties, a society might betray a lack of solidarity and a lack of an honest, or at least coherent commitment, to values such as wellbeing and autonomy.

Second, I mentioned above that public discourse, public policy and legislation have an expressive component and can, as Lessig argued, contribute towards a phenomenon's social meaning and our normative expectations towards it. Some might reasonably worry that deontic isolation for CLE might express the normative expectation that once a life is considered complete, or maybe even should be considered complete, a normal option is for it to be ended. Moreover, like the obesity example above, deontic isolation might express the normative expectation that if individuals suffer - and such suffering falls outside the formal responsibilities of our healthcare system - then it is up to the individual rather than society to deal with it. So, while deontic isolation can seem innocuous enough, we should take seriously the normative meaning such deontic isolation might construct. Again, while this point comes with empirical uncertainty, we should still give it some credence.

I hope this shows why the Contextual Argument matters. Now I still must defend premise 2. Again, I here do not assess (i), i.e. the question as to whether individual instances would be permissible and/or right. My focus is on (ii). I mentioned above that autonomy and wellbeing are typically seen to be the main reasons that can together justify medical euthanasia. So, to assess premise 2, we should primarily focus on antecedent autonomy and wellbeing-related duties in the causal moral history of CLE cases. While there might be other avenues for prevention, remember that I understand autonomy and wellbeing so broadly as to cover most of them. Accordingly, to defend Premise 2, it is enough to show that we fail to discharge our central preventive duties, namely those relating to autonomy and wellbeing.

Let us start with autonomy. 
A simple yet tenaciously popular story about autonomy goes like this: if a person wants to do something voluntarily and without harming anyone else, the state ought not to stop her. To respect a person's autonomy implies only negative duties, namely not to interfere with a person's actions. This simple picture, however, has drawn sustained criticism from philosophers and bioethicists. When a person expresses a wish to do something, then theories of autonomy should not completely ignore the social relations within which she makes decisions, her personal history up to this point, her psychological profile, and the options she can choose from. Decisions do not happen in a biographical or social vacuum. Accordingly, most theorists these days believe that a concern for people's autonomy implies a much richer set of collective and individual duties.

What, then, is autonomy? As a working notion, I assume that autonomy is about the ability to pursue one's conception of the good or to shape the content of one's own life. Autonomy is often thought to require three dimensions, the first being (Raz 1986):

Choice dimension: Which options are open to me and which ones are closed?

Being able to lead an autonomous life requires a suitable range of options to choose from. If state and society are concerned with people's autonomy, they have a duty to ensure that citizens have a good range of options. Moreover, to ensure individual choice, such duties extend far beyond leaving individuals alone.' Lack of money, bad health and so on can all reduce the range of options a person will have (Cohen 2011; Schmidt 2016; Venkatapuram 2013).

The second dimension is:

Status dimension: in what kind of social relations do I stand to other people? Am I subject to other people's dominating control?

According to neo-republican theorists, being a free person requires being free from dominating power relations (Lovett 2010; Pettit 1997, 2012, 2014; Skinner 2012). A person $A$ is dominated by another agent $B$ (either an individual or a collective agent), if $B$ has uncontrolled power over $A$ 's life. ${ }^{10}$

10 Socio-political freedom in the liberal tradition is typically about the choice dimension, including views that focus on the absence of interpersonal constraints (Berlin 1969; Carter 1999; Miller 1983; Steiner 1994) and views focusing on capabilities (Cohen 2011, 196-97; 
Finally, one needs enough autonomy in a psychological sense to pursue one's conception of the good.

Psychological dimension: do my decisions reflect desires that are truly my own? Do I have the rational capacity to make good decisions given my aims?

Volitional autonomy requires acting from desires or preferences that are sufficiently one's own (Christman 1991; Frankfurt 1971; Garnett 2014; Oshana 2006). Manipulation, peer pressure, brainwashing, addictions, and so on can hinder your capacity to pursue your conception of the good. Moreover, autonomy also requires adequate cognitive capacities and decision-making powers. Operating under dangerously misguided empirical assumptions or lacking basic decision-making capacities would hamper your capacity to lead a selfdetermined life.

Given this more nuanced notion of autonomy, a concern with autonomy clearly implies a rich set of collective duties. The first important lesson shows us where the burden of proof lies for euthanasia cases. A concern with a person's autonomy along the choice dimension itself always gives us a pro tanto reason not to kill. Without life, one does not have any options to choose from." So, if we want to justify a practice of euthanasia via autonomy, we must show that we discharge our autonomy-related duties in view of the stronger burden of proof that, ceteris paribus, killing always decreases a person's future options and thereby her autonomy.

Are we meeting our collective autonomy duties regarding CLE cases? Such duties are not exclusively reactive but also preventive. The focus on prevention is central also because CLE candidates typically develop their death wish over quite some time. And our duties to prevent existential suffering applies both to those currently at risk and those possibly at risk in the future. Moreover, to meet our duties requires suitable institutions that (i) research what reduces autonomy in old age and what interventions would help effectively, (ii) formulate resulting duties, (iii) assign responsibilities to carry out such duties, (iv) and reliably discharge such duties.

Kramer 2003; Parijs 1997, 20-24; Schmidt 2016; Sen 1999; Venkatapuram 2013). Critics of republicanism argue that republican concerns are accounted for within liberal theories (Bruin 2009; Carter 2009; Kramer 2009; Lang 2012; Shnayderman 2012). However, because dominating power relations matter on both theoretical frameworks, either intrinsically or instrumentally, we can leave this dispute aside.

11 See Carter (2013) and Schmidt (2017) on intertemporal freedom. 
In qualitative interviews, people mention several reasons for viewing their lives as completed. Some suggest an institutional gap such that society fails to meet all its autonomy-related duties.

First, candidates for CLE frequently mention a fear of becoming too dependent on others (Schnabel et al. 2016, chap. 4.3; van Wijngaarden, Leget, and Goossensen 2015; Wijngaarden 2016). Prima facie, we could plausibly do more to secure independence for elderly people. Better health technologies, stronger social inclusion, the prevention of poverty in old age, and other efforts could be researched and, if conducive, undertaken to increase people's sense of independence. Furthermore, conditions of care need to be structured such that those cared for retain a sense of agency. For those fearing complete dependency in the future, better advance care planning might help. More control over one's end-of-life care can often ease such fears (Schnabel et al. 2016, 154).

Second, people often mention that they are socially isolated, that they feel like their lives lack a purpose, and that they no longer feel useful to other people (Schnabel et al. 2016, chap. 4.3; van Wijngaarden, Leget, and Goossensen 2015; Wijngaarden 2016). This also matters for people's autonomy. For the most part, people's conception of the good life and life plans involve a sense of purpose that is socially embedded. Older, socially isolated people might often feel a loss of purpose when they lack meaningful social roles or simply do not feel needed. We here should make an effort to explore how far better social integration, better opportunities for volunteering, memberships in clubs and so on can increase the ways in which older people might still pursue activities they perceive to be meaningful. Finally, some people find it more difficult than others to adapt to ageing. Many people report a sense of loss of physical and mental capacities (I say more on this below). Better education programs might improve people's capacities to adapt to the challenges that come from ageing, thereby preserving greater agency.

Our societal autonomy duties are far richer than a simple duty not to interfere with people. We likely fail to sufficiently meet such obligations towards elderly people who find their loss of autonomy unbearable. But I now argue that the case is more obvious and stronger for wellbeing-related duties.

Do we Discharge Our Wellbeing Obligations?

Collectively, we should do much more to advance the wellbeing of the elderly; only then would CLE not seem contextually problematic.

Note first that, contrary to common misperception, old age is typically not a time of unhappiness - statistically, quite the opposite. Alongside children and 
young adults, old people are the happiest bunch (Blanchflower and Oswald 2008). Because old age is potentially one of the happiest times in our lives, existential suffering strikes me as particularly sad.

Again, I operate with a broad understanding of wellbeing. ${ }^{2}$ We just need to assume that people who request euthanasia - or are at risk of developing such a wish - experience little wellbeing and that people's self-reported wellbeing (and lack thereof) provides us with important information about their wellbeing, which seems fair enough.

Are we doing enough to prevent people from experiencing existential suffering? Once again, we should enquire, first, why people tend to see their lives as completed and, second, whether we have a suitable institutional setup that sufficiently seeks to address such factors. Some common themes across different studies and study populations suggest several collective wellbeing duties. Here are some examples.

Many older people report difficulties adjusting to old age. One set of collective duties requires preparing the elderly to adjust physically and emotionally to the challenges of ageing. For this, geriatric care should address both physical care but also broader personalized help. One might reasonably worry that existing care is set up to secure physical functioning yet somewhat neglects the emotional challenges around ageing. Educational programs might be important. Mindfulness interventions and meditation might contribute towards helping persons adjust emotionally to ageing. Evidence suggests that such interventions can significantly improve wellbeing among the elderly (FountainZaragoza and Prakash 2017). Cognitive behavior therapy and personalized narrative treatment might also be avenues to address people's sense of loss of purpose and perspective (Kissane, Spruyt, and Aranda 2000). In this context, some people also express that they mourn no longer being able to pursue the activities that once really mattered to them. Good care might help them adjust to such emotional challenges. Support could also be provided to help find new activities. Evidence suggests that learning a new skill and taking up a new hobby, particularly if social, tends to increase wellbeing (Howell et al. 2011).

12 As said before, I here understand 'wellbeing' broadly and remain neutral on what the 'philosophically correct' account of wellbeing might be. But I would insist giving great weight to people's subjective experiences rather than focusing primarily on 'objective goods.' For example, if a patient judges her own life to be going well despite strong physical limitations, then we typically give great weight to her judgment even if she might lack many 'objective goods.' Furthermore, this subjective component allows us to draw on psychology and social science research on reported wellbeing and life satisfaction (work that matters across many different theories of wellbeing). See Haybron (2008), Sumner (1996), and Parfit (1984, chap. Appendix I) for work on wellbeing. 
Again, much of these points are exploratory. But, as mentioned above and exemplified in Crevice $3^{*}$, central antecedent duties start with duties to explore what preventive options exist in the first place.

But the most common reason for existential suffering across studies is loneliness and social isolation. Relatedly, many reported feeling being of no use to others and lacking a purpose. Our most central duty arguably is to explore options to reduce isolation and loneliness among the elderly. This can range from better efforts to identify lonely elderly people, better volunteering opportunities, better facilities for social interactions, removal of financial constraints (many report not being able to participate because they cannot afford it) and, more abstractly, reshaping society in a way that integrates older people more in social activities and sees them as valuable members capable of contributing to society. ${ }^{13}$ We might just be at the beginning of understanding what is sometimes called the 'loneliness epidemic' which disproportionally affects the elderly. But understanding and reducing loneliness is a key component in addressing lowered wellbeing in elderly populations. We currently have strong institutions to provide medical care but lack suitable institutional responsibilities to address loneliness. When it comes to the so-called 'loneliness epidemic,' I think we encounter a serious responsibility gap.

\section{What about Medical Euthanasia?}

In the last two sections, I argued that we encounter an institutional responsibility gap in completed life cases and that, unless we make efforts to fill this gap, a legalized official CLE practice would be contextually problematic. Accordingly, debates around CLE risk engaging in problematic deontic isolation by trying to separate the permissibility of CLE instances from the wider societal preventive duties preceding CLE'S causal moral history.

Remember that proponents of legalizing CLE typically espouse the Arbitrary Difference Argument, arguing that the same considerations that speak for legalizing medical euthanasia should straightforwardly justify CLE too. CLE is, in a sense, the next logical step. Foregrounding contextual justification shows that this might be too quick. In this context, it is helpful to compare medical euthanasia and existential suffering in terms of contextual justification. I argue now that our practice of medical euthanasia in countries like the NL is not contextually problematic to the extent that CLE would be (provided we

\footnotetext{
13 See Jopling (2015) for an overview of possible interventions (with a UK focus) and Hommerson and Van Tilburg (2015) for a report with a Dutch perspective.
} 
do not fill the responsibility gap). This difference shows that the Argument from Arbitrary Difference is a little quick. If we keep everything else equal, CLE would not just be a simple, or obvious, extension of our current euthanasia legislation. But, at the same time, my discussion will also reveal interesting similarities between medical euthanasia and CLE, suggesting that the difference in terms of contextual justification might be one of degree rather than kind.

To discharge antecedent duties, and to avoid euthanasia becoming contextually problematic, implies a system that researches what actions are available and have reasonable chances of success, formulates relevant duties, assigns responsibilities for such duties, and reliably discharges such duties. Prima facie, we have some reason to think that countries like the Netherlands live up to that requirement for medical euthanasia. The Netherlands has universal and high-quality healthcare and a good health research and public health system. Moreover, Dutch euthanasia laws specify that doctors must exercise due care and offer treatments (other than euthanasia). The Dutch system, first, includes a system that assigns institutional responsibilities to investigate what duties there are to discharge. Second, the system next specifies what duties we have towards potential euthanasia candidates in our public health and healthcare system. Third, the system next assigns responsibilities to agents to attend to these duties. Finally, given the quality of the health system in the Netherlands, the system is relatively reliable in discharging such duties. As a society, the Netherlands, and countries like it, invest much time, resources, and effort into investigating what actions are available, formulating relevant duties, assigning responsibilities for such duties, and discharging them.

We can contrast this institutional approach to responsibility with how as a society we approach non-medical suffering. Because existential suffering is considered non-medical, it escapes the responsibility-assigning health system. To a significant extent, we take existential suffering to institutionally fall outside the purview of societal responsibility in a way that we do not for the immediate causes of medical euthanasia. There is thus a significant difference between the contextual justification of CLE and medical euthanasia just by how we delineate what we, societally, are responsible for and what we are not.

However, I now somewhat qualify this difference. To this end, consider first how the structure of my argument can apply to medical euthanasia too.

For medical euthanasia too, we can imagine clear cases of failures to attend to antecedent duties. For example, countries that could afford universal medical care but exclude the poor have a hard time justifying 'universal' medical euthanasia. Or imagine the country's poor work in unregulated, hazardous work conditions that regularly and predictably cause cancer. That such a country does not discharge its antecedent duties does, of course, not imply that 
they have thereby absolved themselves of a duty to offer medical euthanasia. If we believe that autonomy and wellbeing in principle require that medical euthanasia be available, then such countries have a general duty to make voluntary euthanasia available. But given that they in principle have such a duty, it follows that they also ought to discharge antecedent duties pertaining to euthanasia's causal moral history, where this should minimally include universal healthcare and appropriate public health measures.

Note how this applies to medical euthanasia in psychiatric cases too. The Netherlands allows euthanasia in psychiatric cases, whereas Canada, for example, does not. Of course, many other important questions arise (Griffiths 1995; Cowley 2013; Wijsbek 2012). For example, can doctors be confident enough to judge that a patient's mental illness will not get better in the future? But the Contextual Justification Argument applies here too. If we believe that autonomy and wellbeing can in principle justify euthanasia in mental health cases, then this implies we have collective duties to invest in good mental health research, provide good treatment options, and attend to the social determinants of mental health. This would provide another reason as to why we ought to see mental health not purely as a medical issue but one that also requires a societal response. ${ }^{14}$

So, we can encounter clear institutional responsibility gaps that would make medical euthanasia contextually problematic too. But someone may object that, first, even less obvious institutional gaps for medical euthanasia could make it contextually problematic, second, that such gaps do exist in countries like the Netherlands such that, third, medical euthanasia is just as contextually problematic as CLE. Consider two such arguments. ${ }^{15}$

First, some cases of medical euthanasia could be prevented through interventions falling outside a country's formal medical sector. For example, unhealthy behavior causally contributes to the incidence of cancer - and morbidity and mortality more generally - including unhealthy diet, lack of exercise, smoking, alcohol consumption, and so on. Moreover, some evidence suggests that loneliness and social isolation also affect morbidity and mortality

14 If we care about preventing death, then there are additional arguments: people with mental illness have a higher risk of committing suicide, account for the majority of suicide victims, and have higher all-cause mortality rates (Chesney, Goodwin, and Fazel 2014). Focusing on morbidity also gives us reason to give more priority to mental health, as it ranks among the leading contributors to the global disease burden (on some measures accounting for around $30 \%$ of all years lived with disability (Vigo, Thornicroft, and Atun 2016)).

15 Thanks to an anonymous reviewer for pressing me on these issues. 
rates and might thus affect the incidence of euthanasia requests (Caspi and Roberts 2001; Shankar et al. 2011). Moreover, people sometimes suffer more strongly from a given health condition if they are socially isolated (Wall 2002). If so, loneliness potentially matters for how likely someone is to request euthanasia. The last points are particularly interesting, because I earlier identified loneliness and social isolation as issues generating antecedent duties for CLE. So, even though medical euthanasia is about medical conditions, similar 'nonmedical' factors bring up the question as to whether, just like in CLE cases, society fails to attend to all its antecedent duties.

Second, patients who request medical euthanasia often cite loss of autonomy, not being able to engage in activities that make life enjoyable, losing control of bodily functions, loss of dignity, and being a burden for others as some of their reasons for requesting medical euthanasia ("Oregon Death with Dignity Act: Annual Report" 2019, 12; Emanuel et al. 2016, 85). Not all these reasons are 'medical.' Does this not suggest a significant overlap between the reasons for medical euthanasia and those for CLE?

Notice a similarity between what could make CLE contextually problematic and the above arguments. In both cases, we seem to reduce our responsibilities by defining some issues as being 'non-medical.' Yet if many causes and pathways for prevention and alleviation are social or 'non-medical' in nature, then it can sometimes seem arbitrary to exclude them as antecedent moral duties. ${ }^{16}$ However, while significant, I do not think the above considerations imply that medical euthanasia in countries like the Netherlands is equally contextually problematic as CLE. I wish to maintain that there is still an institutional responsibility gap for CLE in a way that there is not - or to a lesser extent - for medical euthanasia. Here are four arguments.

First, whether antecedent duties apply also depends on how remediable the causes are. While reduced qualify of life and autonomy might be reasons in regard to both medical and non-medical euthanasia, they are potentially different and more remediable for CLE. The vast majority of medical euthanasia requests are from cancer patients ("Oregon Death with Dignity Act: Annual Report" 2019, 11; Emanuel et al. 2016, 85). In such cases, reduced quality of life, loss of autonomy and reduced physical ability to engage in the activities one enjoys typically come from greatly reduced physical functioning, and so do loss of control over one's body and an associated sense of loss of dignity. The natural path to restoring autonomy, abilities to engage in valued activities, social participation, and so on, would then be to restore physical functioning. And,

16 This argument might be further strengthened by worries that palliative care should be given greater importance in medical care. 
accordingly, we require in medical euthanasia cases that available treatments for the physical conditions have been exhausted. We ought, of course, also try to create suitable opportunities for people with reduced physical functionings to partake in social life and to increase their autonomy, as far as possible. Yet the physical constraints of most medical euthanasia patients, for example cancer patients or those with neurodegenerative conditions, put significant limits on how far we can restore their ability to exercise autonomy, do the activities they enjoyed before their condition, and actively partake in social life. In CLE cases, in contrast, the sources of existential suffering are typically not insurmountable physical limitations. Rather, people might typically be physically capable to partake in social life yet, for one reason or another, lack external social opportunities. Given that the source is often to a significant extent external, the collective duty to improve social participation is typically more direct and feasible.

Second, we should encounter differences in how immediate and predictable causes are. Someone's antecedent duty to prevent something immediate and predictable should be stronger, other things being equal, than someone's duty to prevent something bad that is remote, uncertain, and hard to predict. Assume that loneliness increases morbidity and mortality. Still, the causal connection between individual instances of loneliness and instances of medical euthanasia requests is much harder to establish and less robust than it is when someone explicitly cites loneliness as a major reason for existential suffering. I do not mean to suggest that this absolves society of attending to social causes of increased morbidity and mortality - far from it. I only suggest that our duties become stronger when preventive actions more foreseeably and immediately prevent bad outcomes and that this makes the link between loneliness and euthanasia requests typically tighter for CLE cases than for medical euthanasia.

Third, as mentioned earlier, whether we have antecedent duties and how strong they are depends also on which other moral reasons apply. We clearly have other duties and values besides preventing existential suffering and lowering morbidity and mortality. For example, I earlier cited behavioral problems such as overeating and alcohol consumption as contributors to morbidity and mortality. But tackling such issues often generates tricky moral conflicts. For example, drastic behavioral interventions, such as paternalistic food and alcohol policies, are sometimes perceived to conflict with respect for individual freedom and autonomy. Or sometimes things that are bad for us, such as sugary food, might also be sources of joy and increase our quality of life. Critics warn against 'health imperialism' where health trumps all other values (such as freedom and fun). Such conflicts show, I think, that we should not immediately 
infer that we have violated an antecedent duty whenever we could do more to reduce morbidity and mortality. Finally, such interventions also generate financial opportunity costs. Solidaristic societies should take its health obligations seriously, but we also have other collective duties (defense, education, infrastructure, etc.). How strong antecedent duties are also depends on these other competing moral values and opportunity costs.

Finally, I earlier argued that having an antecedent duty to prevent something bad from happening can apply even when one does not yet know exactly how to prevent it from happening (see Crevice $3^{*}$ ). Attending to one's duties does not imply that one always solves all problems perfectly. For many behavioral problems, countries like the Netherlands do invest a lot of resources, both financial and intellectual, to figure out ways to tackle them. Most societies go to great lengths to improve population health, or at least try to find out how they could do so, because it is not always obvious how best to do so. Plausibly, for CLE in contrast, we treat many of its causes as falling outside our responsibilities. An important part of closing the responsibility gap would involve making a greater institutional effort to investigate what possibilities we have for reducing elderly suffering.

The similarities and differences between how we approach medical euthanasia and CLE is instructive. My argument, in principle, can apply to both. Yet, while there is an interesting overlap in our antecedent duties regarding ME and CLE, I argued that our institutional responsibility gap regarding CLE in countries like the Netherlands currently seems greater than regarding medical euthanasia, which makes deontic isolation regarding CLE more contextually problematic.

Before closing, I now consider two objections and one limitation to my arguments.

First, I earlier argued that to generate an antecedent duty, preventive efforts need to be reasonably effective and beneficial. We do not seem morally required to spend half our government budget on preventing a few cases of existential suffering. And as argued above, we sometimes think our preventive duties for medical cases can be limited by other valuable considerations, such as freedom and opportunity costs. But one might now worry that if genuine completed life cases are few and preventive efforts expensive, would the opportunity costs not be excessive? 
Much depends on empirics here. But I think two likely empirical aspects disarm this objection. First, societal changes and interventions are unlikely to be prohibitively costly. Many of the changes are societal - such as a better integration of the elderly - without being particularly cost-intensive. Moreover, some of the more specific interventions, such as those tackling loneliness or mindfulness programs, are not expensive either, particularly when compared with medical interventions. Second, some of the issues identified, loneliness in particular, affect many elderly people most of whom are not CLE candidates. Moreover, as mentioned, loneliness exacerbates health problems (American Psychological Association 2017; Holt-Lunstad et al. 2015). So, tackling loneliness potentially comes with great additional benefits such as making people healthier and happier. Finally, our societies are becoming older such that aggregate elderly wellbeing should become a more important policy goal. Accordingly, preventive duties for CLE might thus be cost-effective in producing many important benefits far beyond completed life cases.

Second, consider a philosophical objection next. Some objectors might question whether wellbeing can legitimately be an aim for public institutions and public policy in today's pluralist societies. Liberal neutrality - a somewhat popular view in political philosophy - holds that public policies should not aim to promote particular conceptions of the good or rely on them to justify institutions and public policies (Larmore 1987; Patten 2012; Rawls 1993). On some renderings, liberal neutrality implies that the state should not try to promote people's wellbeing. Wellbeing is primarily a function of people's conceptions of the good. Promoting wellbeing would thus fall into the private sphere and outside the scope of the state. If correct, the Contextual Justification Argument would be in trouble. ${ }^{17}$

How should one respond? Of course, we could just reject liberal neutrality, at least in its strong form. (For the record, I believe that we should.) ${ }^{18}$ I suspect that most non-philosophers would probably believe that societies should, where they can, facilitate conditions in which individuals experience more rather than less wellbeing. But we need not settle the wider philosophical

17 One might claim, conversely, that liberal neutrality speaks against the legalization of CLE, as listing criteria as to when someone's life should be considered 'complete' implies nonneutral judgments about the good. Proponents of CLE might retort that it is only the person's own judgment that matters, and that CLE should not be conditional on 'objective criteria' for when a person's life is completed. Given limited scope, I exclude this discussion here. Thanks to an anonymous reviewer for this point. 
debate here. In this article, I assume that wellbeing - understood very broadly is a central and indispensable value in euthanasia legislation. A reader who believes we should never invoke wellbeing to justify legislation would also have to dismiss wellbeing as a reason in medical cases. But, as I said earlier, leaving out wellbeing completely would conflict with, first, the reasons provided by defenders of CLE and, second, the principles underlying Dutch law and euthanasia laws in other countries. My response to the neutrality worry is this: if the promotion of wellbeing can be invoked to override our strong moral and legal norms against killing, then it can be invoked to justify solidaristic efforts to prevent people from suffering so badly that they wish they were dead. Responsibility for non-medical welfare and suffering are often thought to fall into people's private spheres. For those who take welfare seriously in euthanasia cases, however, the Contextual Justification Argument implies that welfare again in a very broad sense - should be a central goal of public policy and legislation. We should not expect individuals to be the sole architects of their own happiness.

Third, I have argued that we make a mistake if we consider the permissibility of CLE separately from its causal moral history. An objector might now respond that even if I am right about this, my argument might lead people to give us the worst of both worlds. We might end up ignoring both the morality of euthanasia and our antecedent duties. Consider a variation of Crevice 1:

Crevice ${ }^{*}$ : Everything is as in Crevice 1, only this time it is illegal for A to kill $\mathrm{B}$. As a result, B lives on for two weeks greatly suffering the whole time.

The objector might now claim that my arguments might lead to an outcome much like Crevice $1^{*}$ : not only do we fail to discharge our antecedent duties regarding existential suffering, we also force CLE candidates to suffer needlessly.

My argument here does not require refuting this worry. I have merely argued against deontic isolation in cases such as Crevice and CLE. I have left it open whether, keeping everything else equal, it would be better to allow CLE. I have cited and listed possible reasons for and against the permissibility of CLE above but have, myself, left that question open. Indeed, my argument was precisely that we should not frame our discussion in terms of this 'other things equal question.'

But, for what it's worth, while I agree that the outcome is morally worse in Crevice $1^{*}$ than it is in Crevice 1, I think that our current situation regarding CLE is importantly different from Crevice $1^{*}$. Moving from our legal status quo 
towards legalizing CLE would not be like changing Crevice $1^{*}$ into Crevice 1 . Here are two reasons to believe - although only tentatively so - that even if CLE can be permissible, it might currently not be necessary or even helpful to legalize an official CLE practice. ${ }^{19}$

First, as mentioned earlier, deontic isolation and legalizing CLE might make it less likely that we will do more to prevent what causes people to want CLE. Potentially, legalized CLE might make euthanasia a more normal societal response to elderly suffering and we might end up doing less than we currently do by way of prevention. Moreover, CLE might, in problematic ways, change the social meaning of existential suffering and euthanasia by, for example, potentially normalizing euthanasia as a response to elderly suffering. As said earlier, such empirical worries are hard to assess. Yet that does not mean we should ignore them, only that we should not give them full credence.

Second, some general reflection about suicide legislation should also give us pause. In general, legislation should not make it too easy for people to end their lives. People often commit suicide in the spur of the moment and most survivors never try again. One of the best ways to prevent suicide is to make it more difficult ("The Non-Profit That Figured out How to Massively Cut Suicide Rates" 2018). So, we have strong general reason not to make euthanasia and assisted suicide too easy. Existing medical euthanasia legislation reflects this cautious attitude, as it builds relatively strict requirements into the law. Now, let us next assume that our objector is right in that it would be morally desirable for at least some of the potential CLE candidates to have the option to end their lives (assuming all else equal). In response, we could point out that some putative cases of CLE in the Netherlands might already be covered by mental health and 'accumulative' medical euthanasia. What about the cases currently not covered? Here, even if you believe that suicide should be possible, you need not believe it should be easily available. Currently, committing suicide is not easy but certainly possible for CLE candidates, if they invest some time and effort. CLE candidates are typically healthy and have functioning cognitive capacities. This being so, they typically have enough capacities to find ways to end their lives should they have a strong and persistent death wish. And anecdotal evidence suggests some such elderly people can indeed be resourceful in finding ways to end their lives. For example, some buy different ingredients to mix them into a 'death powder' (Steenbergen 2017). Overall then, even if you assume that people with existential suffering should have the option to end

19 The Schnabel report also arrives at this conclusion and provides additional arguments for it (Schnabel et al. 2016). 
their lives, they currently do have the option, which makes the situation very different from Crevice $3^{*}$. That such an option is neither 'officially approved' nor easy to exercise might not be such a bad thing.

As a final limitation or qualification of my argument, consider that while my main arguments have been about 'countries like the Netherlands,' I mainly talked about the Netherlands. Rather than yielding conclusive judgments on CLE in other countries, the Contextual Justification Argument thus provides more of a blueprint to be filled in when charting relevant differences and similarities between countries (for both medical and non-medical euthanasia). For example, Canada, Belgium and Switzerland have also legalized medical euthanasia and offer comparable levels of universal healthcare as the Netherlands. But we would also have to enquire into the elderly population who would request CLE and whether these countries undertake sufficient systematic efforts to prevent non-medical suffering among the elderly. Some countries might be genuinely different in this respect. Common wisdom has it, for example, that Southern European and Latin American countries are comparatively better at integrating the elderly - with images popping up of septuagenarians playing boule or sprightly grandmothers partying with their grandchildren. If so, such social differences would matter for the claims advanced in this paper.

\section{Conclusions}

Proponents of CLE argue that the main reasons for medical euthanasia apply to CLE too. Suffering can be real without being medical. Accordingly, extending existing euthanasia legislation to non-medical cases is, in a sense, the logical next step. In this article, I have argued that such arguments are too quick. Rather than focusing on the permissibility of individual cases of euthanasia, I argued we should first zoom out to consider euthanasia as a legal and social practice in its societal context. It is a moral mistake to assess instances of CLE individually whilst ignoring their causal moral history. So, whether CLE cases are permissible or not, an appropriate approach to existential suffering would require a serious societal commitment to addressing its causes. Such a commitment would require a system that assigns responsibilities for researching, assessing, assigning, and pursuing interventions and societal changes that prevent existential suffering. I have outlined some areas for such solidaristic efforts, one pressing duty hereby being a collective effort to respond to what some call the 'loneliness epidemic' among the elderly. I think this gives analytical and moral substance to our vague feeling that there is something 
socially undesirable about wanting to rush towards legalizing CLE without at the same time carefully exploring ways to collectively prevent elderly suffering.

I showed that the Contextual Justification Argument also matters beyond CLE. In medical cases too, we make a moral mistake, if we focus on the moral permissibility of legalizing euthanasia without seeking to discharge preventive solidaristic duties. If autonomy and wellbeing justify legalizing medical euthanasia, then this implies, for example, that countries have a duty to have universal healthcare and a functioning public health and health research system, as well as some other societal duties that bear on morbidity and mortality. Similarly, if autonomy and wellbeing can justify voluntary euthanasia in psychiatric cases, then this implies collective duties to intensify our efforts to prevent and treat mental illness.

But I still maintain that there is a difference between medical euthanasia and CLE, at least in how countries like the Netherlands deal with it. For medical conditions, countries like the Netherlands have a reasonably comprehensive and solidaristic system - public health and healthcare - in which responsibilities are assigned and discharged that seek to prevent people wishing to die because of medical conditions (even if imperfectly). Because of this difference, legalizing CLE without attending to our antecedent duties would be contextually problematic in a way that legalized medical euthanasia currently is not, or at least to a lesser extent. Solidarity should be at the heart of our response to suffering, whether it be somatic, psychiatric, or existential.

\section{Acknowledgments}

I would like to thank Marco Meyer, Hans Harbers, Maarten Verkerk, and two anonymous reviewers for their helpful written feedback.

\section{Biographical Note}

Andreas T. Schmidt is an Assistant Professor of Political Philosophy at the Faculty of Philosophy at the University of Groningen in the Netherlands. He works in political theory, normative and applied ethics, and the philosophy of public policy. He is particularly interested in freedom, inequality, consequentialism, longtermism, behavioural policies, public health, and biomedical ethics. 


\section{Bibliography}

American Psychological Association. 2017. "Social Isolation, Loneliness Could Be Greater Threat to Public Health than Obesity." Science Daily. August 5, 2017. https:// www.sciencedaily.com/releases/2017/08/170805165319.htm.

Arneson, Richard. 2017. "Liberal Neutrality on the Good: An Autopsy." unpublished. http://philosophyfaculty.ucsd.edu/faculty/rarneson/neutrality.pdf.

Berlin, Isaiah. 1969. "Two Concepts of Liberty." In Four Essays on Liberty, 118-72. Oxford: Oxford University Press.

Blanchflower, David G., and Andrew J. Oswald. 2008. "Is Well-Being U-Shaped over the Life Cycle?" Social Science \& Medicine 66 (8): 1733-49. https://doi.org/10.1016/j .socscimed.2008.01.030.

Brock, Dan W. 1992. "Voluntary Active Euthanasia." Hastings Center Report 22 (2):10-22. https://doi.org/10.2307/3562560.

Bruin, Boudewijn de. 2009. "Liberal and Republican Freedom*." Journal of Political Philosophy 17 (4): 418-39. https://doi.org/10.1111/j.1467-9760.2009.00334.x.

Carter, Ian. 1999. A Measure of Freedom. Oxford: Oxford University Press.

Carter, Ian. 2009. "How Are Power and Unfreedom Related." In Republicanism and Political Theory, edited by Cécile Laborde and John W. Maynor, 58-82. Oxford: Blackwell Publishing.

Carter, Ian. 2013. "Distributing Freedom over Whole Lives." In Arguing about Justice: Essays for Philippe Van Parijs, edited by Axel Gosseries and Philippe Vanderborght, 135-43. Hors Collections. Louvain-la-Neuve: Presses universitaires de Louvain.

Caspi, Avshalom, and Brent W. Roberts. 2001. "Personality Development Across the Life Course: The Argument for Change and Continuity." Psychological Inquiry 12 (2): 49-66. https://doi.org/10.1207/S15327965PLI1202_01.

Chesney, Edward, Guy M. Goodwin, and Seena Fazel. 2014. "Risks of All-Cause and Suicide Mortality in Mental Disorders: A Meta-Review." World Psychiatry 13 (2):153-60. https://doi.org/10.1002/wps.20128.

Christman, John. 1991. “Autonomy and Personal History." Canadian Journal of Philosophy 21 (1): 1-24.

Cohen, G. A. 1997. "Where the Action Is: On the Site of Distributive Justice." Philosophy \& Public Affairs 26 (1): 3-30. https://doi.org/10.1111/j.1088-4963.1997.tbooo48.x.

Cohen, G. A. 2011. "Freedom and Money." In On the Currency of Egalitarian Justice, and Other Essays in Political Philosophy, 166-200. Princeton University Press.

Cowley, Christopher. 2013. "Euthanasia in Psychiatry Can Never Be Justified. A Reply to Wijsbek." Theoretical Medicine and Bioethics 34 (3): 227-38. https://doi.org/10.1007/ s11017-013-9252-6.

De Haan, Jurriaan. 2002. “The Ethics of Euthanasia: Advocates' Perspectives.” Bioethics 16 (2): 154-72. https://doi.org/10.1111/1467-8519.00276. 
Dijkstra, Pia. 2016. "Voorstel van Wet van Het Lid Pia Dijkstra Houdende Toetsing van Levenseindebegeleiding van Ouderen Op Verzoek En Tot Wijziging van Het Wetboek van Strafrecht, de Wet Op de Beroepen in de Individuele Gezondheidszorg En Enkele Andere Wetten (Wet Toetsing Levenseindebegeleiding van Ouderen Op Verzoek)." https://d66.nl/wet-voltooid-leven-pia-dijkstra/.

"Dutch Coalition Negotiations: 'Compromise Reached on Ethical Issues." 2017. DutchNews.Nl. August 15, 2017. http://www.dutchnews.nl/news/archives/2017/08/ dutch-coalition-negotiations-compromise-reached-on-ethical-issues/.

Emanuel, Ezekiel J., Bregje D. Onwuteaka-Philipsen, John W. Urwin, and Joachim Cohen. 2016. "Attitudes and Practices of Euthanasia and Physician-Assisted Suicide in the United States, Canada, and Europe." JAMA 316 (1): 79-90. https://doi.org/10.10o1/ jama.2016.8499.

Fountain-Zaragoza, Stephanie, and Ruchika Shaurya Prakash. 2017. "Mindfulness Training for Healthy Aging: Impact on Attention, Well-Being, and Inflammation." Frontiers in Aging Neuroscience 9: 11. https://doi.org/10.3389/fnagi.2017.00011.

Frankfurt, Harry G. 1971. "Freedom of the Will and the Concept of a Person." The Journal of Philosophy 68 (1): 5-20. https://doi.org/10.2307/2024717.

Garnett, Michael. 2014. "The Autonomous Life: A Pure Social View." Australasian Journal of Philosophy 92 (1): 143-58. https://doi.org/10.1080/00048402.2013.765899.

Griffiths, John. 1995. "Assisted Suicide in the Netherlands: The Chabot Case." The Modern Law Review 58 (2): 232-48. https://doi.org/10.111/j.1468-2230.1995.tbo20o6.x.

Haybron, Daniel M. 2008. The Pursuit of Unhappiness : The Elusive Psychology of WellBeing: The Elusive Psychology of Well-Being. Oxford University Press.

Holt-Lunstad, Julianne, Timothy B. Smith, Mark Baker, Tyler Harris, and David Stephenson. 2015. "Loneliness and Social Isolation as Risk Factors for Mortality: A Meta-Analytic Review." Perspectives on Psychological Science 10 (2): 227-37. https:// doi.org/10.1177/1745691614568352.

Hommerson, S.M., and T.G. Van Tilburg. 2015. "Voorkomen of Verminderen van Eenzaamheid in de Langdurige Zorg: Wetenschappelijk Onderbouwde Inspiratie Uit Het Buitenland." Vrije Universiteit Amsterdam, afdeling Sociologie. https:// www.samentegeneenzaamheid.nl/sites/wte/files/onderzoek-voorkomen-of -verminderen-van-eenzaamheid-in-de-langdurige-zorg-coalitie-erbij.pdf.

Howell, Ryan T., David Chenot, Graham Hill, and Colleen J. Howell. 2011. "Momentary Happiness: The Role of Psychological Need Satisfaction." Journal of Happiness Studies 12 (1): 1-15. https://doi.org/10.1007/s10902-009-9166-1.

Huxtable, Richard, and Maaike Möller. 2007. “'Setting a Principled Boundary'? Euthanasia as a Response to 'Life Fatigue'” Bioethics 21 (3): 117-26. https://doi .org/10.1111/j.1467-8519.2007.00535.x.

Jopling, Kate. 2015. "Promising Approaches to Reducing Loneliness and Isolation in Later Life." ID202422. Campaign to End Loneliness. 
Kissane, D. W., O. Spruyt, and S. Aranda. 2000. "Palliative Care - New Approaches to the Problem of Suffering." Australian and New Zealand Journal of Medicine 30 (3): 377-84. https://doi.org/10.1111/j.1445-5994.200o.tboo841.x.

Kissane, David W. 2004. "The Contribution of Demoralization to End of Life Decisionmaking." Hastings Center Report 34 (4): 21-31. https://doi.org/10.2307/352869o.

Kramer, Matthew H. 2003. The Quality of Freedom. Oxford: Oxford University Press.

Kramer, Matthew H. 2009. "Liberty and Domination." In Republicanism and Political Theory, edited by Cecile Laborde and John Maynor, 31-57. Oxford: Blackwell Publishing.

Lang, Gerald. 2012. "Invigilating Republican Liberty." The Philosophical Quarterly 62 (247): 273-93. https://doi.org/10.1111/j.1467-9213.2011.00015.x.

Larmore, Charles E. 1987. Patterns of Moral Complexity. Cambridge University Press.

Lessig, Lawrence. 1995. "The Regulation of Social Meaning." The University of Chicago Law Review 62 (3): 943-1045. https://doi.org/10.2307/160o054.

Lovett, Frank. 2010. A General Theory of Domination and Justice. Oxford: Oxford University Press.

Miller, David. 1983. "Constraints on Freedom." Ethics 94 (1): 66-86.

"Oregon Death with Dignity Act:Annual Report." 2019. Public Health Division, Center for Health Statistics. https://www.oregon.gov/oha/PH/PROVIDERPARTNERRESOURC ES/EVALUATIONRESEARCH/DEATHWITHDIGNITYACT/Pages/ar-index.aspx.

Oshana, Marina. 2006. Personal Autonomy in Society. Aldershot: Ashgate Publishing, Ltd.

Parfit, Derek. 1984. Reasons and Persons. Oxford: Oxford University Press.

Parijs Philippe Van. 1997. Real Freedom for All: What (If Anything) Can Justify Capitalism? Oxford: Clarendon Press.

Patten, Alan. 2012. "Liberal Neutrality: A Reinterpretation and Defense*." Journal of Political Philosophy 20 (3):249-72. https://doi.org/10.1111/j.1467-9760.2011.00406.x.

Pettit, Philip. 1997. Republicanism: A Theory of Freedom and Government: A Theory of Freedom and Government. Oxford: Oxford University Press.

Pettit, Philip. 2012. On the People's Terms: A Republican Theory and Model of Democracy. Cambridge: Cambridge University Press.

Pettit, Philip. 2014. Just Freedom: A Moral Compass for a Complex World. New York: W. W. Norton \& Company.

Pierson, Paul. 2000. "Increasing Returns, Path Dependence, and the Study of Politics." The American Political Science Review 94 (2): 251-67. https://doi.org/10.2307/ 2586011.

Prainsack, Barbara, and Alena Buyx. 2012. "SOLIDARITY IN CONTEMPORARY BIOETHICS - TOWARDS A NEW APPROACH.” Bioethics 26 (7): 343-5o. https://doi .org/10.1111/j.1467-8519.2012.01987.x.

Rawls, John. 1993. Political Liberalism. New York: Columbia University Press. 
Raz, Joseph. 1986. The Morality of Freedom. Oxford: Oxford University Press.

Schmidt, Andreas T. 2016. "Abilities and the Sources of Unfreedom." Ethics 127 (1): 179207. https://doi.org/10.1086/687335.

Schmidt, Andreas T. 2017. "An Unresolved Problem: Freedom across Lifetimes." Philosophical Studies 174 (6): 1413-38. https://doi.org/10.1007/s11098-016-0765-5.

Schnabel, P., B. Meyboom-de Jong, W.J. Schudel, C.P.M. Cleiren, P.A.M. Mevis, M.J. Verkerk, A. van der Heide, G. Hesselmann, and L.F. Stultiëns. 2016. "Voltooid Leven: Over Hulp Bij Zelfdoding Aan Mensen Die Hun Leven Voltooid Achten." Den Haag: Adviescommissie Voltooid Leven.

Sen, Amartya. 1999. Development as Freedom. 1st. ed. New York: Knopf.

Shankar, Aparna, Anne McMunn, Banks James, and Andrew Steptoe. 2011. "Loneliness, Social Isolation, and Behavioral and Biological Health Indicators in Older Adults." Health Psychology: Official Journal of the Division of Health Psychology, American Psychological Association 30 (4): 377-85. https://doi.org/10.1037/aoo22826.

Sher, George. 1997. Beyond Neutrality: Perfectionism and Politics. Vol. 110. 438. Cambridge University Press.

Shnayderman, Ronen. 2012. "Liberal vs. Republican Notions of Freedom." Political Studies 60 (1): 44-58. https://doi.org/10.1111/j.1467-9248.2011.009oo.x.

Skinner, Quentin. 2012. Liberty Before Liberalism. Cambridge: Cambridge University Press.

Steenbergen, Enzo van. 2017. "Dodelijk poeder in een feestelijke envelop." NRC. 2017. https://www.nrc.nl/nieuws/2017/10/13/dodelijk-poeder-in-een-feestelijke-envelop -13486566-a1577235.

Steiner, Hillel. 1994. An Essay on Rights. Oxford: Wiley.

Sumner, L. W. 1996. Welfare, Happiness, and Ethics. Clarendon Press.

Sumner, L. W. 2011. Assisted Death: A Study in Ethics and Law. Oxford: Oxford University Press.

"The Non-Profit That Figured out How to Massively Cut Suicide Rates." 2018. 8oooohours.Org. March 7, 2018. https://800oohours.org/2018/03/leah-utyasheva -pesticide-suicide-prevention/.

Varelius, Jukka. 2014. "Medical Expertise, Existential Suffering and Ending Life." Journal of Medical Ethics 40 (2): 104-7. https://doi.org/10.1136/medethics-2012-100812.

Venkatapuram, Sridhar. 2013. Health Justice: An Argument from the Capabilities Approach. John Wiley \& Sons.

Vigo, Daniel, Graham Thornicroft, and Rifat Atun. 2016. "Estimating the True Global Burden of Mental Illness." The Lancet Psychiatry 3 (2):171-78. https://doi.org/10.1016/ S2215-0366(15)00505-2.

Wall, Patrick. 2002. Pain: The Science of Suffering. Columbia University Press.

Wijngaarden, Els van. 2016. Voltooid leven: over leven en willen sterven. Atlas Contact, Uitgeverij. 
Wijngaarden, Els van, Carlo Leget, and Anne Goossensen. 2015. "Ready to Give up on Life: The Lived Experience of Elderly People Who Feel Life Is Completed and No Longer Worth Living." Social Science \& Medicine 138 (August): 257-64. https://doi .org/10.1016/j.socscimed.2015.05.015.

Wijsbek, Henri. 2012. “To Thine Own Self Be True': On the Loss of Integrity as a Kind of Suffering." Bioethics 26 (1): 1-7. https://doi.org/10.1111/j.1467-8519.2010.01801.x.

Young, Robert. 2007. Medically Assisted Death. Cambridge University Press.

Young, Robert. 2016. "Voluntary Euthanasia." In The Stanford Encyclopedia of Philosophy, edited by Edward N. Zalta, 2016. Metaphysics Research Lab, Stanford University. https://plato.stanford.edu/archives/fall2016/entries/euthanasia-voluntary/. 